\title{
Changing Demographics and Prevalence of Body Lice among Homeless Persons, Marseille, France
}

\author{
Tran Duc Anh Ly, Youssoupha Touré, \\ Clément Calloix, Sékéné Badiaga, \\ Didier Raoult, Hervé Tissot-Dupont, \\ Philippe Brouqui, Philippe Gautret
}

The prevalence of body lice among 2,288 sheltered homeless persons in the city of Marseille during 2000-2017 was $12.2 \%$ and significantly decreased over time. We report a positive association between body lice infestations and older age, duration of stays in France for migrants, frequent consumption of alcohol, and tobacco smoking.

$\mathrm{H}$ omeless persons are predisposed to infections because of their poor physical state and lack of hygiene; therefore, outbreaks of contagious diseases are more prevalent among them $(1,2)$. Body lice infestation prevalence in homeless populations has been shown to be $19.0 \%-68.0 \%$ $(3-7)$. However, despite the capacity of these ectoparasites to be vectors of several diseases, study of infestation has been minimal among the homeless. To identify potential risk factors for body lice infestation, we analyzed the demographics and chronic medical conditions of the homeless population from Marseille and their variations during 18 years.

\section{The Study}

The protocol for this study was reviewed and approved by the Institutional Review Board and Ethics Committee of Assitance Publique Hôpitaux de Marseille (2010A01406-33). We conducted cross-sectional, 1-day surveys during 2000-2017 in 2 Marseille shelters (A and B) housing a limit of 300 homeless persons each with a high turnover. Most persons in shelters A and B stay for nights only with no time limitation, but shelter A has a special day/night unit with a 35-bed capacity, dedicated to high-risk sedentary homeless persons whose characteristics include a high level of poverty, poor hygiene, alcoholism, and mental illness. We informed participants of our ongoing study of infectious diseases and that they could receive a complete medical examination free of charge and treatment when needed. Participants volunteered and signed informed consent documents. A medical team

Author affiliation: Aix-Marseille-Université, Marseille, France

DOI: https://doi.org/10.3201/eid2311.170516 interviewed participants by using a standardized questionnaire and physically examined them for the presence of ectoparasites (online Technical Appendix, https://wwwnc. cdc.gov/EID/article/23/11/17-0516-Techapp1.pdf). Several delousing measures were administered over time at the 2 shelters (online Technical Appendix).

We recruited 2,288 persons, $57 \%$ of whom were enrolled in shelter A (Table 1). Most participants were middle-aged men, most of whom were originally from North Africa and settled in France $>12$ years before the survey was done. A total of 334 (33.2\%) migrants reported recurrent travel to their country of origin. Homelessness lasting $>1$ year accounted for $44.1 \%$ of cases.

The proportion of France- and Eastern Europe-born homeless persons decreased significantly over time $\left(\mathrm{R}^{2}=\right.$ 0.68 and 0.55 , respectively) and the proportion from North Africa increased $\left(\mathrm{R}^{2}=0.64\right)$ (online Technical Appendix Figure 1). The mean duration of stays in France for migrants and the mean duration of homelessness decreased significantly over time $\left(\mathrm{R}^{2}=0.71\right.$ and 0.53 , respectively; online Technical Appendix Figure 2).

Among participants, 75\% reported smoking tobacco, $60 \%$ consuming alcohol, and 20\% consuming cannabis (online Technical Appendix Figure 2). In addition, 25\% of participants had an elevated body mass index; $5.8 \%$ were underweight. Tobacco smoking and frequent alcohol consumption decreased significantly during the study period $\left(\mathrm{R}^{2}=0.61\right.$ and 0.94 , respectively; online Technical Appendix Figure 3).

We recorded a high prevalence of pruritus (548 persons $[26.9 \%])$, associated with scratch lesions in 306 $(17.4 \%)$ persons. Overall, $382(23.3 \%)$ participants had lice. The prevalence of differing types of lice was body lice, $12.2 \%(\mathrm{n}=242)$; head lice, $4.5 \%(\mathrm{n}=87)$; crab lice, $3.2 \%(\mathrm{n}=53)$; and scabies, $2.8 \%(\mathrm{n}=50)$. The prevalence of body lice decreased significantly during the study period $\left(\mathrm{R}^{2}=0.58\right)$ (online Technical Appendix Figure 3).

Body lice prevalence was higher in shelter A than in shelter $\mathrm{B}$, increased with age and duration of homelessness, and was higher among persons born in France compared with others (Table 1). Body lice were less common in persons born in North Africa than in those born elsewhere. Body lice prevalence in migrants increased with duration 
Table 1. Demographics and results of univariate and multivariate analysis of risk factors for body lice infestation among homeless persons, Marseille, France, 2000-2017*

\begin{tabular}{|c|c|c|c|c|}
\hline \multirow[b]{2}{*}{ Demographics } & \multirow[b]{2}{*}{ Total } & \multirow{2}{*}{$\begin{array}{l}\text { Body lice } \\
\text { prevalence }\end{array}$} & \multicolumn{2}{|c|}{ Odds ratio $(95 \% \mathrm{Cl}), \mathrm{p}$ value } \\
\hline & & & Univariate analysis & Multivariate analysis \\
\hline \multicolumn{5}{|l|}{ Shelter used } \\
\hline A† & $1,305(57.0)$ & $90(10.5)$ & $1.33(1.01-1.76), 0.041$ & 3.45 (1.37-8.66), 0.008 \\
\hline $\mathrm{B}$ & $983(43.0)$ & $152(13.5)$ & & \\
\hline \multicolumn{5}{|l|}{ Sex } \\
\hline M & $2,161(95.4)$ & $236(12.6)$ & & \\
\hline $\mathrm{F}$ & $105(4.6)$ & $5(5.7)$ & & \\
\hline \multicolumn{5}{|l|}{ Age, $y$} \\
\hline Mean (SD) & $43.1(15.0)$ & NA & & \\
\hline Range & $18-86$ & NA & & \\
\hline$<25$ & $221(10.0)$ & $4(2.1)$ & & \\
\hline $25-50$ & $1,291(58.5)$ & $105(9.5)$ & & \\
\hline$>50$ & $694(31.5)$ & $121(19.8)$ & $2.70(2.04-3.57),<0.0001$ & $2.47(1.14-5.34), 0.022$ \\
\hline \multicolumn{5}{|l|}{ Birthplace } \\
\hline France mainland & $597(26.4)$ & $95(19.2)$ & $2.18(1.64-2.89),<0.0001$ & \\
\hline France overseas territories & $23(1.0)$ & $6(30.0)$ & & \\
\hline North Africa & $1,109(49.0)$ & $95(9.6)$ & $0.62(0.47-0.81),<0.0001$ & \\
\hline Sub-Saharan Africa & $123(5.4)$ & $14(13.0)$ & & \\
\hline Eastern Europe & $270(11.9)$ & $16(7.0)$ & & \\
\hline Western Europe & $77(3.4)$ & $10(14.3)$ & & \\
\hline Asia & $51(2.3)$ & $3(6.7)$ & & \\
\hline Other & $11(0.5)$ & 0 & & \\
\hline \multicolumn{5}{|l|}{ Duration of residence in France, $y$} \\
\hline Mean (SD) & $12.2(16.8)$ & NA & & \\
\hline Range & $0-75$ & NA & & \\
\hline$<1$ & $390(38.8)$ & $8(2.3)$ & & \\
\hline $1-5$ & $176(17.5)$ & $4(2.6)$ & & \\
\hline$>5 \ddagger$ & $438(43.6)$ & $41(11.6)$ & $5.46(2.83-10.55),<0.0001$ & $4.28(1.79-10.23), 0.001$ \\
\hline $\begin{array}{l}\text { Visited country of origin since } \\
\text { immigration }\end{array}$ & $334(33.2)$ & $20(7.4)$ & & \\
\hline $\begin{array}{l}\text { Total no. visits to country of origin since } \\
\text { immigration }\end{array}$ & $672(66.8)$ & $27(4.8)$ & & \\
\hline \multicolumn{5}{|l|}{ Duration of homelessness, y } \\
\hline Mean & 3.8 & NA & & \\
\hline Range & $0-57$ & NA & & \\
\hline$<1$ & $1,218(55.9)$ & $66(6.3)$ & & \\
\hline $1-5$ & $443(20.3)$ & $52(13.4)$ & & \\
\hline$>5$ & $518(23.8)$ & $112(24.7)$ & $3.67(2.77-4.88),<0.0001$ & \\
\hline $\begin{array}{l}\text { *Values are no. (\%) persons except as indicat } \\
\text { included in the univariate model. NA, not appli } \\
\text { †Includes high-risk homeless special unit (33 } \\
\text { †North African migrants only: body lice preval } \\
\mathrm{Cl} 2.41-16.95 ; p<0.0001) \text {. }\end{array}$ & $\begin{array}{l}\text { Blank cells indic } \\
\text { e. } \\
\text { e } 300 \text { beds in th } \\
\text { was } 1.6 \% \text { in pe }\end{array}$ & $\begin{array}{l}\text { statistically ins } \\
\text { helter). } \\
\text { ons living in Fra }\end{array}$ & $\begin{array}{l}\text { nificant results; variables with a pr } \\
\text { ce for }<5 \text { y vs. } 9.3 \% \text { in those living }\end{array}$ & $\begin{array}{l}\text { Alence }<5.0 \% \text { were not } \\
\text { France for }>5 \text { y (OR } 6.39,95 \%\end{array}$ \\
\hline
\end{tabular}

of stay in France. Consuming alcohol frequently, smoking tobacco, and being underweight were associated with an increased risk for body lice (Table 2). In multivariate analyses, only housing in shelter A, older age, duration of stay in France for migrants, frequent consumption of alcohol, and smoking tobacco remained associated with an increased prevalence of body lice. Smoking, alcohol consumption, and underweight prevalence varied according to place of birth (online Technical Appendix).

\section{Conclusions}

In this survey, we observed significant changes over time in the demographic characteristics of the homeless population in Marseille. Overall, France-born, long-term homeless persons were progressively replaced by migrants of North Africa origin, who had a shorter duration of homelessness. Concurrently, the prevalence of frequent alcohol consumption and tobacco smoking decreased over time. France-born homeless persons were more prone to alcoholism and smoking habits, and those originating from North Africa were less likely to be frequent consumers of alcohol.

The decrease over time in overall body lice prevalence could be attributed to the changes in the characteristics of the population and also to the effects of delousing interventions conducted in the shelters. We identified several independent risk factors for body lice, including older age, residence duration in France of migrants, frequent alcohol consumption, and tobacco smoking. The latter 2 factors are likely correlative because they are markers of poor self-care, which may be associated with risk of body lice infestation. 
Table 2. Results of univariate and multivariate analysis of risk factors for body lice infestation among homeless persons, Marseille, France, 2000-2017*

\begin{tabular}{|c|c|c|c|c|}
\hline \multirow[b]{2}{*}{ Risk factor } & \multirow[b]{2}{*}{ Total } & \multirow{2}{*}{$\begin{array}{l}\text { Body lice } \\
\text { prevalence }\end{array}$} & \multicolumn{2}{|c|}{ Odds ratio $(95 \% \mathrm{Cl}), \mathrm{p}$ value } \\
\hline & & & Univariate analysis & Multivariate analysis \\
\hline \multicolumn{5}{|l|}{ Substance use } \\
\hline \multicolumn{5}{|l|}{ Alcohol } \\
\hline Never & $892(39.8)$ & $29(3.7)$ & & \\
\hline Sometimes & $623(27.8)$ & $55(9.8)$ & & \\
\hline Frequently & $729(32.5)$ & $155(25.1)$ & $5.01(3.77-6.68),<0.0001$ & $3.93(1.85-8.36),<0.0001$ \\
\hline \multicolumn{5}{|l|}{ Tobacco } \\
\hline Never & $576(25.5)$ & $20(4.0)$ & & \\
\hline Yes & $1680(74.5)$ & $218(14.9)$ & $4.16(2.60-6.65),<0.0001$ & 2.46 (1.04-5.79), 0.04 \\
\hline Cannabis (never) & $921(82.1)$ & $70(8.1)$ & & \\
\hline Cannabis & $201(17.9)$ & $23(11.9)$ & & \\
\hline Injected substances & $19(1.1)$ & $5(27.8)$ & & \\
\hline Nasally inhaled substances & $40(3.0)$ & $7(24.1)$ & & \\
\hline Drug substitutes & $25(1.5)$ & $5(21.7)$ & & \\
\hline \multicolumn{5}{|l|}{ Medical conditions } \\
\hline COPD & $38(9.9)$ & $11(5.6)$ & & \\
\hline Asthma & $63(6.1)$ & $3(6.5)$ & & \\
\hline Bronchitis & $44(4.3)$ & $4(12.1)$ & & \\
\hline Cancer & $6(0.9)$ & 0 & & \\
\hline Diabetes & $47(5.8)$ & $1(2.2)$ & & \\
\hline Hepatitis & $22(2.8)$ & 7 (33.3) & & \\
\hline History of pulmonary TB & $55(4.2)$ & $3(7.1)$ & & \\
\hline \multicolumn{5}{|l|}{ Weight } \\
\hline Mean BMI (SD) & $23.8(4.2)$ & & & \\
\hline BMI range & $13.5-65.0$ & & & \\
\hline Underweight & $97(5.8)$ & $14(17.9)$ & 2.998 (1.53-5.90), 0.001 & \\
\hline Normal weight & $1,009(60.3)$ & $93(10.8)$ & & \\
\hline Overweight & $439(26.2)$ & $23(6.0)$ & & \\
\hline Obesity & $129(7.7)$ & $11(9.6)$ & & \\
\hline
\end{tabular}

These results correlate with the observation of very high prevalence of body lice found in a specific survey by our team of 33 high-risk homeless persons from shelter $\mathrm{A}$ in which an $84.9 \%$ prevalence was found, compared to an estimated $22.0 \%$ prevalence in the overall population of shelter A over the same period of time (8). Those results corroborate our observation of a higher overall prevalence of body lice in shelter A than in shelter B. The subpopulation of the homeless persons with an elevated level of high-risk behaviors, housed in the special sector of shelter A, may have acted as a source of reinfestation for the other persons in this shelter. Unfortunately, being housed in shelter A's special unit was not documented on a regular basis in our surveys.

We found no other published study addressing risk factor analysis for body lice among sheltered homeless persons. In a Paris survey, A. Arnaud et al. conducted a risk factor analysis among homeless persons sleeping in public areas only, and body lice prevalence was associated with a history of pubic lice, begging, and not attending municipal showers (9). In a survey of homeless persons in San Francisco who were consulting for possible lice infestation, male gender, African American ethnicity, and sleeping outdoors were significantly associated with having body lice (7).

Our observation that the strongest determinant of body lice in the homeless was alcoholism correlates with previous observations that trench fever is associated with a history of alcoholism (10-13). Because body lice are known vectors of trench fever, which was the most frequently reported vectorborne infection identified in homeless persons in Europe and the US during 1990-2014, targeted removal of lice should specifically reduce its incidence in this population $(14,15)$.

Our survey has several limitations. The homeless persons were not randomly selected, so those who had skin disease symptoms might have been more prone to enroll in the survey because a free medical examination was offered. Our results represent only homeless persons provided with shelter and cannot be extrapolated to those sleeping outside, where a higher prevalence of body lice has been reported (9).

Notwithstanding these limitations, these results demonstrate the value of investigating the homeless in shelters directly to estimate the prevalence of body lice and its risk factors. Our survey indicates that demographic factors, addictions, and being underweight are factors associated with body lice risk, which may be used to better target populations for delousing measures.

Dr. Ly is a medical doctor and a PhD student at Aix-Marseille University. His main research interest is epidemiology of diseases in mobile populations. 


\section{References}

1. Fazel S, Geddes JR, Kushel M. The health of homeless people in high-income countries: descriptive epidemiology, health consequences, and clinical and policy recommendations. Lancet. 2014;384:1529-40. http://dx.doi.org/10.1016/

S0140-6736(14)61132-6

2. Raoult D, Foucault $\mathrm{C}$, Brouqui P. Infections in the homeless. Lancet Infect Dis. 2001;1:77-84. http://dx.doi.org/10.1016/ S1473-3099(01)00062-7

3. Arfi C, Dehen L, Bénassaïa E, Faure P, Farge D, Morel P, et al. Dermatologic consultation in a precarious situation: a prospective medical and social study at the Hôpital Saint-Louis in Paris [in French]. Ann Dermatol Venereol. 1999;126:682-6.

4. Guibal F, de La Salmonière P, Rybojad M, Hadjrabia S, Dehen L, Arlet G. High seroprevalence to Bartonella quintana in homeless patients with cutaneous parasitic infestations in downtown Paris. J Am Acad Dermatol. 2001;44:219-23. http://dx.doi.org/10.1067/ mjd.2001.110062

5. Rydkina EB, Roux V, Gagua EM, Predtechenski AB, Tarasevich IV, Raoult D. Bartonella quintana in body lice collected from homeless persons in Russia. Emerg Infect Dis. 1999;5:176-8. http://dx.doi.org/10.3201/eid0501.990126

6. Bonilla DL, Kabeya H, Henn J, Kramer VL, Kosoy MY. Bartonella quintana in body lice and head lice from homeless persons, San Francisco, California, USA. Emerg Infect Dis. 2009;15:912-5. http://dx.doi.org/10.3201/eid1506.090054

7. Bonilla DL, Cole-Porse C, Kjemtrup A, Osikowicz L, Kosoy M. Risk factors for human lice and bartonellosis among the homeless, San Francisco, California, USA. Emerg Infect Dis. 2014;20:164551. http://dx.doi.org/10.3201/eid2010.131655

8. Foucault C, Ranque S, Badiaga S, Rovery C, Raoult D, Brouqui P. Oral ivermectin in the treatment of body lice. J Infect Dis. 2006;193:474-6. http://dx.doi.org/10.1086/499279

9. Arnaud A, Chosidow O, Détrez MA, Bitar D, Huber F, Foulet F, et al. Prevalences of scabies and pediculosis corporis among homeless people in the Paris region: results from two randomized cross-sectional surveys (HYTPEAC study). Br J Dermatol. 2016;174:104-12. http://dx.doi.org/10.1111/ bjd.14226

10. Brouqui P, Houpikian P, Dupont HT, Toubiana P, Obadia Y, Lafay V, et al. Survey of the seroprevalence of Bartonella quintana in homeless people. Clin Infect Dis. 1996;23:756-9. http://dx.doi.org/10.1093/clinids/23.4.756

11. Brouqui P, Lascola B, Roux V, Raoult D. Chronic Bartonella quintana bacteremia in homeless patients. N Engl J Med. 1999; 340:184-9. http://dx.doi.org/10.1056/NEJM199901213400303

12. Pons I, Sanfeliu I, Nogueras MM, Sala M, Cervantes M, Amengual MJ, et al. Seroprevalence of Bartonella spp. infection in HIV patients in Catalonia, Spain. BMC Infect Dis. 2008;8:58 http://dx.doi.org/10.1186/1471-2334-8-58

13. Chaloner GL, Harrison TG, Birtles RJ. Bartonella species as a cause of infective endocarditis in the UK. Epidemiol Infect. 2013;141:841-6. http://dx.doi.org/10.1017/S0950268812001185

14. Badiaga S, Brouqui P. Human louse-transmitted infectious diseases. Clin Microbiol Infect. 2012;18:332-7. http://dx.doi.org/10.1111/ j.1469-0691.2012.03778.x

15. Leibler JH, Zakhour CM, Gadhoke P, Gaeta JM. Zoonotic and vector-borne infections among urban homeless and marginalized people in the United States and Europe, 1990-2014. Vector Borne Zoonotic Dis. 2016;16:435-44. http://dx.doi.org/10.1089/ vbz.2015.1863

Address for correspondence: Philippe Gautret, URMITE, IHU,

Méditerranée Infection, 19-21 Boulevard Jean Moulin, 13005 Marseille, France; email: philippe.gautret@club-internet.fr

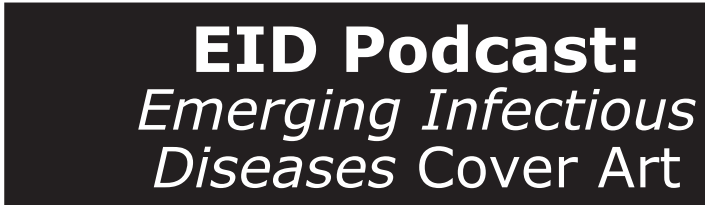

Byron Breedlove, managing editor of the journal, elaborates on aesthetic considerations and historical factors, as well as the complexities of obtaining artwork for Emerging Infectious Diseases.
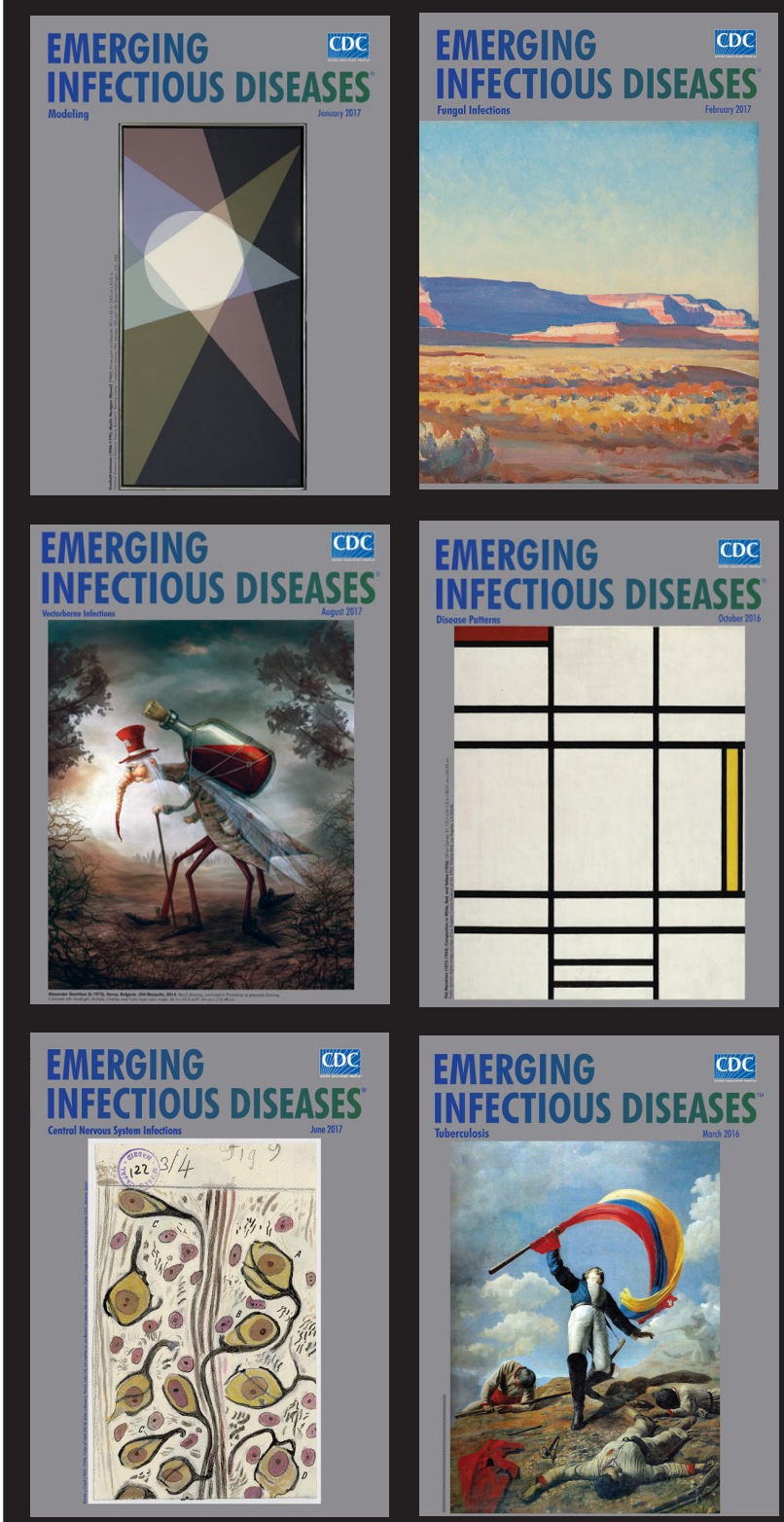

Visit our website to listen: EMERGING INFECTIOUS DISEASES podcasts/player. asp?f=8646224 